\title{
Incidental video-capsule diagnosis of small-bowel Taenia saginata in a patient with recurrent hemorrage due to angiodysplasias
}

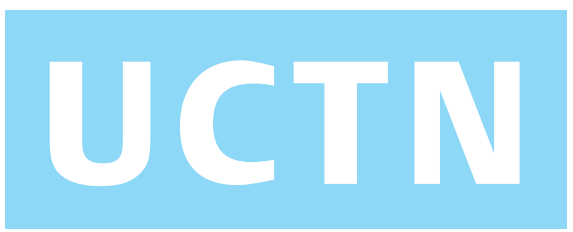

A 75-year-old countryman came to our attention because of persistent iron deficiency anemia that had lasted for a few months. He had previously undergone several diagnostic examinations, including upper endoscopy and colonoscopy, but no cause of chronic hemorrhage had been detected. Intravenous iron supplementation led to improvement of his hematological parameters but recurrent sideropenia was found at follow-up. Following a popularly held belief, he was encouraged to eat raw meat in order to increase his iron intake.

Eventually, a video-capsule endoscopic examination was performed. At least two bright-red angiodysplasias were detected during the examination. To our surprise, a parasite resembling a Taenia tapeworm was also observed (see Figure 1, Videos 1, 2).

The patient was given a single 600-mg dose of praziquantel. After elimination, the parasite was confirmed to be Taenia saginata. Double-balloon ileoscopy was performed to confirm the presence of the two areas of angiodysplasia and to treat them using argon plasma coagulation. To date, microscopic fecal examination has excluded recurrent infection.

Endoscopy_UCTN_Code_CCL_1AC_2AG

H. Martines, E. Fanciulli, G. Menardo Department of Medical Sciences, Ospedale San Paolo, Savona, Italy.
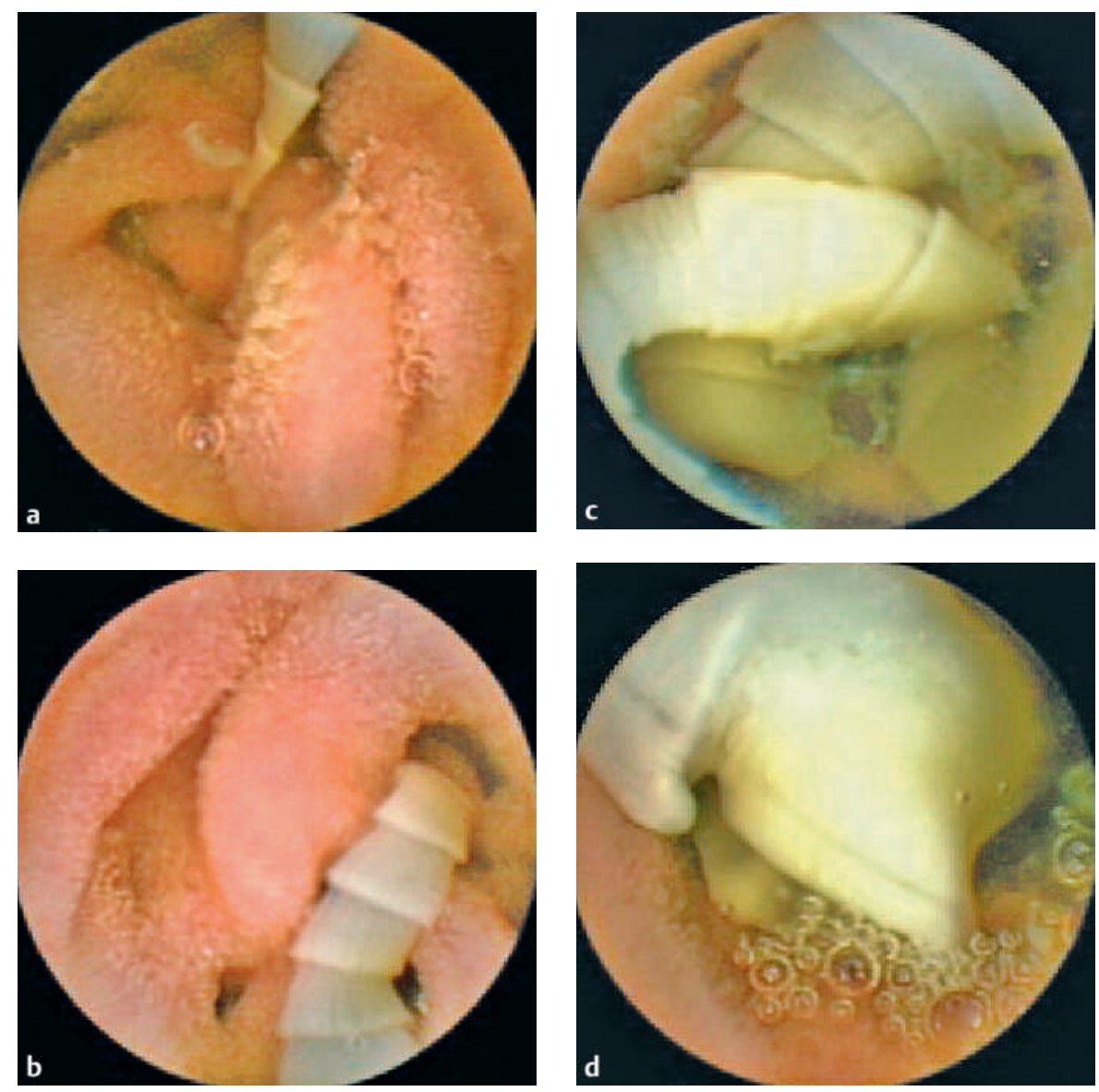

Figure 1 Endoscopic views obtained of the Taenia saginata tapeworm as the capsule progressed through the bowel, showing the appearance of the first proglottids (a, Video $\mathbf{1}$ ); progressively larger proglottids (b); convolutions of the Taenia worm (c); and mature proglottids with obvious genital pores (d). The mature proglottids had a spiral appearance (Video $\mathbf{2}$ ).

Corresponding Author

\section{H. Martines, M.D.}

Department of Medical Sciences Ospedale San Paolo

Via Genova 30

17100 Savona

Italy

Fax: +39-198404224

E-mail: hmartines@libero.it

\section{Video 1 and 2}

online content including video sequences viewable at:

www.thieme-connect.de/ejournals/abstract/ endoscopy/doi/10.1055/s-2006-944648 